\title{
Crop Damage from Sclerotinia Crown Rot and Risk Factors in Pyrethrum
}

Jason B. Scott, Tasmanian Institute of Agriculture (TIA), University of Tasmania-Cradle Coast Campus, Burnie, Tasmania, 7320, Australia; David H. Gent, United States Department of Agriculture-Agricultural Research Service, Forage Seed and Cereal Research Unit, Department of Botany and Plant Pathology, Oregon State University, Corvallis 97331; Sarah J. Pethybridge, The New Zealand Institute of Plant and Food Research Ltd., Private Bag 4704, Lincoln, Christchurch, New Zealand; Tim Groom, Botanical Resources Australia-Agricultural Services Pty. Ltd., Ulverstone, Tasmania, Australia; and Frank S. Hay, TIA, University of Tasmania-Cradle Coast Campus

\begin{abstract}
Scott, J. B., Gent, D. H., Pethybridge, S. J., Groom, T., and Hay, F. S. 2014. Crop damage from Sclerotinia crown rot and risk factors in pyrethrum. Plant Dis. 98:103-111.

Sclerotinia crown rot, caused by Sclerotinia sclerotiorum and S. minor, is a prevalent disease in pyrethrum fields in Australia. Management involves fungicide applications during the rosette stage of plant development from autumn to early spring in fields approaching first harvest. However, estimates of crop damage and the efficacy of these tactics are poorly understood; therefore, plots were established in 86 pyrethrum fields in Tasmania, Australia during 2010 to 2012 to quantify these and to identify risk factors for disease outbreaks. On average, commercial management for Sclerotinia crown rot reduced disease incidence 43 to $67 \%$ compared with nontreated plots. There was a weak but significant relationship between relative increase in flower yield when fungicides were applied and the incidence of crown rot $\left(R^{2}=0.09, P=0.006\right)$, although the mean number of flowers produced was similar regardless

canopy density in spring $(S=0.39, P=0.001)$. Moreover, canopy density in spring was linked by both direct and indirect effects to canopy density during autumn and winter which, in turn, were associated with planting date and previous rain events. Modeling canopy density and disease incidence in autumn correctly categorized disease incidence in spring relative to a threshold of $2 \%$ in $72 \%$ of fields. In a subset of 22 fields monitored over 2 years, canopy density in the autumn following the first harvest had a negative relationship with Sclerotinia crown rot incidence the preceding year $\left(R^{2}=0.23, P=\right.$ 0.006). On average, however, current commercial management efforts provided only small increases in flower yield in the current season and appear best targeted to fields with well-developed plant canopies and Sclerotinia crown rot present during early autumn.
\end{abstract} of fungicide applications. Flower yield was positively associated with
Pyrethrum (Tanacetum cinerariifolium (Trevir.) Sch. Bip.) is a perennial herbaceous member of the Asteraceae family grown for the production of the insecticidal pyrethrins, which are contained within oil glands on the surface of flower achenes (4,32). Pyrethrum production in Australia currently supplies approximately $60 \%$ of the global market for pyrethrins. The Australian industry is based on an intensive production system characterized by mechanization, monocultures with dense plant populations, selection of high-yielding cultivars with synchronous flower development, and high inputs of fertility and water (18). In this production system, pyrethrum fields can remain productive for three or more years. Elsewhere, pyrethrum typically is grown on a subsistence basis as a low-input crop (13).

One of the factors associated with early discontinuation of a commercial crop is reduced stand density and vigor associated with Sclerotinia crown rot, caused by Sclerotinia minor and $S$. sclerotiorum (18). Sclerotinia spp. are destructive, plurivorous, necrotrophic pathogens of a large range of host species (20), causing significant losses worldwide (2). Sclerotinia spp. can survive for more than 8 years in the soil as melanized sclerotia (1). This survival ability, coupled with the extensive host range of the pathogens and absence of resistance in most hosts, make disease control problematic. Sclerotinia spp. cause two major diseases of pyre-

\section{Corresponding author: J. B. Scott, E-mail: Jason.Scott@utas.edu.au}

Mention of a trademark, proprietary product, or vendor does not constitute a guarantee or warranty of the product by the United States Department of Agriculture and does not imply its approval to the exclusion of the products or vendors that may also be suitable.

Accepted for publication 1 August 2013.

http://dx.doi.org/10.1094/PDIS-06-13-0599-RE

(C) 2014 The American Phytopathological Society thrum (18). First, Sclerotinia crown rot is caused by myceliogenic germination of sclerotia near the soil surface and subsequent infection of the crown leading to wilting and, in severe cases, plant death. The disease is typically observed during the autumn, winter, and early spring months, and has been associated with both $S$. minor and S. sclerotiorum. Sclerotia of both species may germinate carpogenically to produce airborne ascospores which infect flowers during early summer and cause Sclerotinia flower blight (15). Apothecial emergence is also closely synchronized with flower development in pyrethrum (19).

Current management efforts for Sclerotinia crown rot in pyrethrum are centered on regular application of the fungicide procymidone during the autumn and winter, when plants are in the rosette stage. A basic tenet of integrated pest management is management intervention that is informed by the risk of crop damage from a pest (26). Crop damage and yield impacts from Sclerotinia crown rot have not been well characterized in pyrethrum or most other perennial pathosystems, and the economic necessity of disease management efforts require quantification to provide a foundation for both strategic and tactical disease management decisions (21). In this study, we sought to assess the efficacy of current commercial management programs for Sclerotinia crown rot and their association with crop damage. A secondary objective was to clarify risk factors for disease development to identify production situations where management intervention may be justified.

\section{Materials and Methods}

Field sites and data collection. The incidence of Sclerotinia crown rot was assessed in a total of 86 commercial pyrethrum fields in northern Tasmania, Australia during 2010 to 2012. All fields were approaching first harvest and were planted in the preceding spring. Within each field, two plot areas were demarcated for assessment. One did not receive applications of procymidone (Fortress 500; Crop Care Australasia Pty. Ltd.) or other fungicides with known activity against Sclerotinia spp. This was designated 
the nontreated plot. The second plot, marked parallel to the nontreated plot, received fungicide applications in accordance with the commercial applications for that field (referred to herein as the commercial plot). Other commercial practices, including herbicide applications, were identical between each pair of plots. Plot sizes were dependent upon the commercial spray boom width used in a given field; therefore, plots varied between 12 by 10 and 30 by 10 $\mathrm{m}$ in size. In each, field disease assessments were conducted three times each season during mid- to late May, late June to mid-July, and mid-August to mid-September, herein referred to as autumn, winter, and spring, respectively. The mean durations between the first and second disease ratings were 43, 48, and 63 days during 2010, 2011, and 2012, respectively. Between the second and third disease ratings, mean durations were 35,55 , and 55 days during 2010, 2011, and 2012, respectively. The number of fields evaluated was 29, 27, and 30 during 2010, 2011, and 2012, respectively. The incidence of Sclerotinia crown rot was assessed using a 1-by-1-m quadrat divided into 25 squares ( 20 by $20 \mathrm{~cm}$ ) in a 5-by-5 arrangement. At each assessment, the quadrat was arbitrarily placed on top of the crop canopy at 25 positions (sampling units) within each plot $(N=25)$. At each sampling unit, each square was scored for (i) the presence or absence of a pyrethrum plant and (ii) the presence or absence of a pyrethrum plant exhibiting visual symptoms of Sclerotinia crown rot infection. As such, the number of squares with a plant present $(n)$ varied between sampling units (maximum $n=25$ ). Due to its irregular emergence pattern and bushy growth habit, distinguishing individual pyrethrum plants is often difficult or impractical. Therefore, each 20-by-20-cm square was treated as an analogue for an individual plant and, for simplicity, is referred to as such. The estimated mean incidence of diseased plants $(\hat{p})$ was calculated as $\hat{p}=\Sigma x_{i} / \Sigma n_{i}$, where $x_{i}$ is the number of diseased plants and $n_{i}$ is the number of plants present in the $i$ th sampling unit. Site-specific data were collected from each field, including soil type, slope, aspect, planting date, and cultivar. During each disease assessment, estimates of pyrethrum canopy density and the presence or absence of weeds and, specifically, clover (Trifolium spp.) were made in each quadrat and used to calculate means for each field. The centroid of each field was obtained with a handheld GPS unit (eTrex Vista HCx; Garmin International, Inc.) and used as a geospatial reference for obtaining interpolated daily temperature and rain data from the Queensland Department of Natural Resources and Mines Data Drill algorithm at a $5-\mathrm{km}^{2}$ spatial resolution $(8,9,27)$. Errors associated with the use of interpolated data compared with on-site temperature data in northern Tasmania have been described (16). Number and dates of commercial applications of procymidone for each field were recorded.

Yield assessments were made in December of each growing season. Flower yield estimates were made through the use of digital imagery (24). Digital cameras (Canon Powershot G12; Canon Inc.) were mounted on frames at a height of $0.9 \mathrm{~m}$ above the crop canopy with a defined 0.7 -by-0.7-m $\left(0.49 \mathrm{~m}^{2}\right)$ quadrat placed level with the top of the crop canopy. With the software package ImageJ, v. $1.47 \mathrm{~g} \mathrm{(22),} \mathrm{color} \mathrm{thresholding} \mathrm{was} \mathrm{used} \mathrm{to} \mathrm{reduce} \mathrm{images} \mathrm{to} \mathrm{the}$ yellow centers of individual flowers, and the particle analyzer function was used to estimate the number of flowers per quadrat. Thirty images were collected per plot and used to determine the mean flower yield.

Following commercial harvesting in January, plots from a subset of fields from the original 86 were remarked and regrowth of pyrethrum foliage was assessed. Fourteen fields from 2010 and eight fields from 2012 were assessed for regrowth in autumn 2011 and 2013, respectively. Fields were selected based on availability (i.e., some fields were removed from production) and prevalence of Sclerotinia crown rot the preceding year. In mid-May, these fields were evaluated for Sclerotinia crown rot incidence, canopy density, and weed prevalence, as described previously. Both commercial and nontreated plots were subject to the same agronomic practices after harvest.

Crop damage from Sclerotinia crown rot. Relationships between Sclerotinia crown rot and flower yield were examined by mixed models. Disease incidence, expressed as area under the disease progress stairs (AUDPS; 25), and flower yield in nontreated and fungicide-treated plots were modeled as dependent on fungicide treatment, year of the study, and the interaction of these factors. Sites within a year were considered random factors. Flower yield was square root transformed before analysis to normalize residuals. Analyses were conducted using the GLIMMIX procedure in SAS (version 9.3; SAS Institute). The number of fungicide applications made in the commercially managed plots varied among fields depending on the growers' specific management tactics, with individual sites receiving zero to four applications. An analysis was conducted over all 3 years with fixed factors for fungicide treatment and a categorical variable for number of fungicide applications; site was again considered a random factor. Disease incidence and flower yield were compared within each level of fungicide application. The relationship between yield in the nontreated plot versus the corresponding fungicide-treated plot and relative yield gain versus Sclerotinia crown rot incidence were quantified by linear regression using the REG procedure in SAS.

Analysis of variables related to Sclerotinia crown rot incidence and flower yield. Scatterplots were created for several weather variables, plant canopy density, weed prevalence, and disease incidence to understand the univariate relationships. The magnitude of the correlations were assessed by Spearman's rank order correlation coefficient (28). The association of disease incidence and canopy density in autumn led to further quantification of the role of rain and temperature associated with these variables. An appropriate time period for correlating weather, disease, and plant canopy density was determined by an iterative process. The total amount of rain; days with rain greater than $0,1,2$, or $3 \mathrm{~mm}$; and simple degree-days (base 0) (17) were calculated for weekly time periods of 1 to 10 weeks before the autumn disease assessment. The correlations of these variables with autumn disease incidence and plant canopy density were assessed by Spearman's rank order correlation coefficient. The magnitude of the correlations and statistical probability levels were examined and used to select a single time point (i.e., 4 weeks) for inclusion in subsequent analyses.

Correlation analyses described above yielded a complex series of interrelationships among the variables. Combinations of variables with significant and biologically sensible correlations with disease incidence and flower yield were assembled into structural equations and analyzed by path analysis (12). Path analysis was conducted to quantify possible interactions among the variables and to develop models depicting how weather, disease, and plant growth interact to influence disease development and pyrethrum flower yield. Competing models were fitted and the simplest, bestfitting model was selected based on minimizing Akaike's Information Criterion (AIC; 12). Path coefficients (standardized partial regression coefficients weights) were obtained and utilized to calculate indirect and direct effects among the variables in the path diagrams. Direct effects are the standardized path coefficients of a path denoted by an arrow connecting two variables. Indirect effects are the association of one variable with another mediated through other variables. Indirect effects are calculated as the sum of the product of the path coefficients linking two variables. Total effect is the sum of direct and indirect effects (12).

To conduct the analysis, correlation matrices of the variables used in the models were constructed using the CORR procedure in SAS, which were then analyzed using the CALIS procedure. Goodness-of-fit of the models was assessed by the $\chi^{2}$ test, root mean square error approximation coefficient, and residual diagnostics. Each model was fit separately and, among the competing models, the model that minimized AIC was considered the best fitting. The significance of each path was assessed by $t$ tests, and values greater than $|2|$ were considered significant $(\alpha=0.05)$.

Risk factors for Sclerotinia crown rot outbreaks in spring. Based on the correlation and path analyses, a logistic regression model was constructed to quantify the association of autumnal weather, host, and inoculum factors with risk of a severe outbreak of the disease in spring. In Australia, a provisional threshold of $2 \%$ 
of plants with Sclerotinia crown rot is commonly used in pyrethrum production as an action threshold for fungicide applications. The accuracy of this threshold is not addressed in this research. Instead, we accepted that this threshold is used in practice and focused upon how autumnal conditions contribute to risk of disease exceeding this threshold in spring. To carry out the analysis, fields were coded as ' 1 ' if the incidence of affected plants exceeded $2 \%$ in spring and ' 0 ' otherwise. Variables identified by correlation and path analysis as potential determinates of disease development in spring were included as predictor variables. Models were evaluated based on AIC and the Hosmer and Lemeshow goodness-of-fit test. Parsimonious models with low AIC values, reasonable prediction accuracy, and adequate fit diagnostics were selected. Analyses were conducted using the LOGISTIC procedure in SAS.

Influence of Sclerotinia crown rot on regrowth after harvest. To normalize regrowth comparisons across fields, canopy density measurements obtained after the first harvest were used to calculate a new variable for each plot: canopy survival. Canopy survival was defined as autumn canopy density after the first harvest divided by autumn canopy density preceding the first harvest, expressed as a percentage. Canopy survival was compared using Spearman's rank order correlation coefficient to the disease variables (autumn, winter, and spring disease incidence, and AUDPS), weed variables (weed and clover incidence), and canopy variables (autumn, winter, and spring canopy density), as described previously. Sclerotinia crown rot was not observed in any plots following the first harvest and, as such, the incidence of affected plants in year 2 was not included in these analyses.

Based on the correlations obtained above, the relationship between canopy survival and disease incidence was assessed in a mixed-model framework. Canopy survival was modeled as dependent on disease incidence (expressed as AUDPS), fungicide treatment, and the interaction between those factors. Sites within a year were considered random factors.

\section{Results}

Crop damage from Sclerotinia crown rot. Across all 516 observations (86 sites, two plots per site, and three assessment periods), median Sclerotinia crown rot incidence was 0.0068, with 25 and $75 \%$ quartiles of 0.00 and 0.039 , respectively (Fig. 1). Disease incidence was greater than 0.05 in $22.1 \%$ of observations, while $10.9 \%$ of observations were greater than 0.10 . Sclerotinia crown rot was observed at least once in 78 of the nontreated plots and 76 of the commercial plots. Fungicide applications were made in 62 of the 86 fields, with fields receiving, on average, 1.3 fungicide applications (median $=1$ ) per year. Disease incidence (expressed as AUDPS) in the commercial plots was reduced by 68.4 to $77.6 \%$ across years compared with the nontreated plots (Fig. 2A; treatment $P<0.0001)$. Disease incidence was also reduced when analyzed respective to the number of times fungicides were applied (treatment-fungicide application interaction, $P=0.0004$ ). Fungicide applications reduced disease incidence by 43.1 to $64.7 \%$ compared with nontreated plots (Fig. 2B).

Overall treatments effects on flower yield were not detected among years (treatment $P=0.430$ ) or among fungicide application intensities (treatment, $P=0.384$; fungicide application, $P=0.990$; Fig. 2C and D). There was a linear relationship between flower yield and commercial management (Fig. 2E), given by the regression equation $y_{N}=0.722 \times y_{C}+134.2$, where $y_{N}$ represents the nontreated flower yield per quadrat and $y_{C}$ the commercially managed flower yield per quadrat. All parameters were significant at $P$ $<0.0001$, with $R^{2}=0.60$. There was only a weak relationship between relative yield gain from commercial management in relationship to the severity of Sclerotinia crown rot in the nontreated plot (Fig. 2F). The regression fit of the relationship was $y_{G}=0.004$ $\times$ AUDPS -0.01 , where $y_{G}$ is the yield gain. The slope parameter was significantly greater than $0\left(P=0.006, R^{2}=0.09\right)$.

Analysis of variables related to Sclerotinia crown rot incidence and flower yield. Disease incidence between the three sampling periods (and AUDPS) was strongly and positively correlated
(Table 1; $S \geq 0.47, P<0.001$ ). Within a sampling time period, disease incidence was significantly correlated with pyrethrum canopy density $(P \leq 0.020)$, particularly during autumn $(S=0.39, P=$ $0.002)$. Mean canopy density and AUDPS also were positively correlated $(S=0.47, P<0.001)$. The prevalence of clover species and other weeds was negatively associated with disease incidence during any assessment period (Table 2). However, pyrethrum canopy density was negatively associated with clover and weed prevalence in all comparisons. Disease incidence in autumn was negatively correlated with flower yield $(S=-0.23, P=0.037)$, whereas disease incidence at other time points was not. In contrast, canopy density during spring $(S=0.39, P<0.001)$ and, to a lesser degree, winter $(S=0.27, P=0.015)$ was associated with flower yield but not canopy density during autumn.

Correlations between canopy density and disease incidence between sampling periods (e.g., autumn canopy density versus winter canopy density) were significant in all cases $(S \geq 0.47, P<0.001)$. Planting date (expressed as day of year) was negatively associated with canopy density in all sampling periods and mean canopy density $(S=-0.26, P=0.014)$, indicating that earlier planting dates were associated with greater canopy density.

Weather variables that indicated the strongest correlations with the incidence of plants with Sclerotinia crown rot in autumn were for time periods 28 to 49 days preceding the disease assessment (Fig. 3). The magnitude of the correlations and their significance were greatest for the number of days with rain. The patterns of correlation with pyrethrum canopy density were more complicated, with the magnitude of the correlations for the rain variables generally greatest during the 7 to 21 days preceding the canopy density evaluation in autumn. The number of days with rain in the preceding 28 days was selected for further investigation. The number of days with rain in autumn was associated with disease during all assessment periods and AUDPS ( $S \geq 0.23, P \leq 0.033)$ but negatively associated with canopy density in spring $(S=-0.21, P=$ 0.048).

Path diagrams constructed from the correlation matrices depicted a series of linked events in pyrethrum canopy and disease development, terminating in flower yield; two of the best fitting models are presented (Fig. 4). The model with the lowest AIC (Fig.

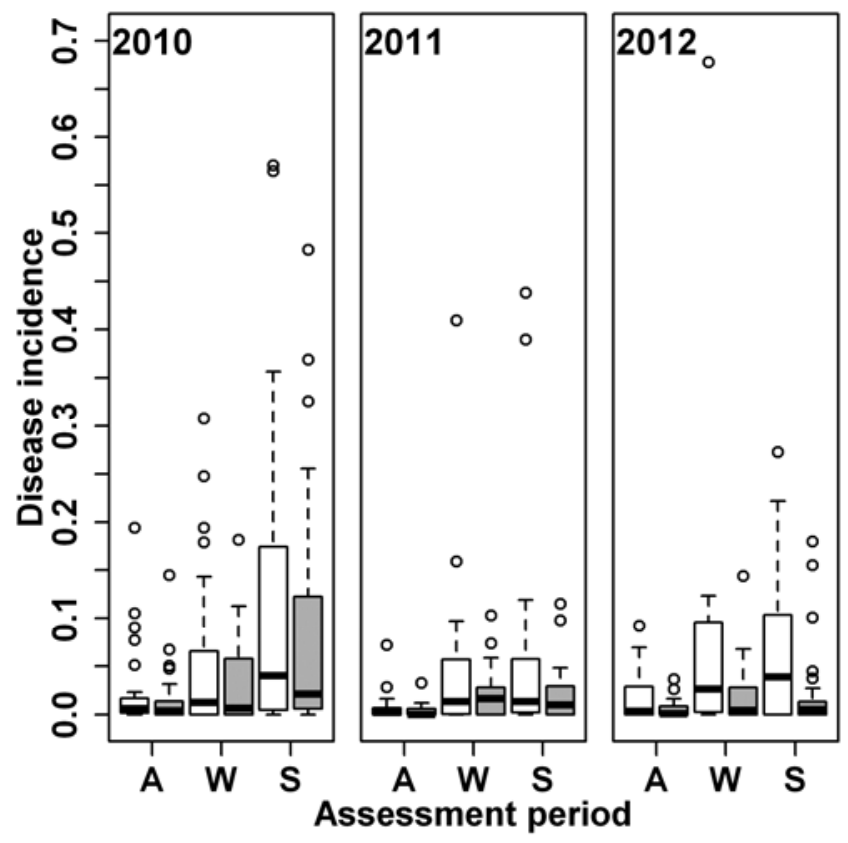

Fig. 1. Distribution of Sclerotinia crown rot incidence observations in nontreated (white) and commercially managed (gray) pyrethrum plots during 2010, 2011, and 2012. All plots were assessed during autumn (A), winter (W), and spring (S). Box extremes represent the 25 and $75 \%$ quartiles, while thick lines represent the median. Whiskers (dashed lines) indicate 1.5 times the interquartile range and circles indicate individual observations beyond this range. 
4B) was structured so that planting date and number of days with rain in the previous 28 days directly affected autumn canopy density. Sclerotinia crown rot incidence in autumn was the consequence of the number of days with rain in the previous 28 days and canopy density during the same period. Canopy density in subsequent time periods was directly affected by the preceding canopy density and incidence of disease. Flower yield in the final path was affected only by spring canopy density. Four paths in the model were not significant ( $t$ statistics less than $|2|)$ but were retained in the model because removing these paths increased AIC (Fig. 4A) and because of their biological relevance. In the best-fitting model, spring canopy density had the largest total effect on flower yield
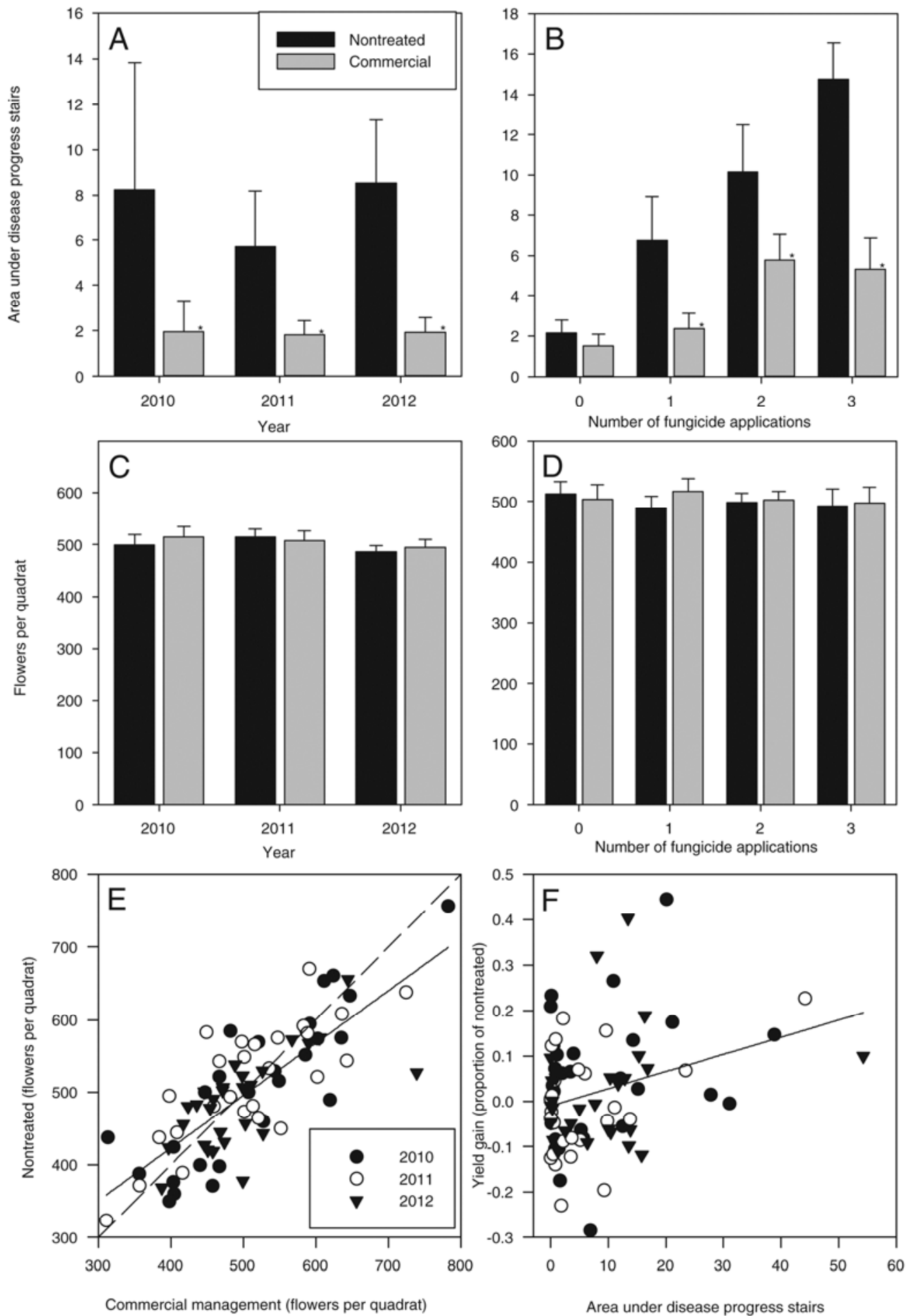

Fig. 2. A, Incidence of Sclerotinia crown rot (expressed as area under the disease progress stairs) in nontreated and commercially managed pyrethrum plots during 2010 to 2012. Asterisks indicate a significant difference $(\alpha=0.05)$ between the nontreated and commercially managed plots within a year based on a mixed-model analysis. $B$, Disease severity in relationship to the number of fungicide applications made in the commercially managed plots. C, Flower yield in nontreated and commercially managed plots during 2010 to 2012. D, Flower yield in relationship to the number of fungicide applications made in the commercially managed plots. A single field in 2012 received four fungicide applications and is included with fields that received three fungicide applications. The incidence of plants with Sclerotinia crown rot in this field was $16.9 \%$ in the nontreated plot and $5.2 \%$ in the commercially managed plot; flower yield was $7.3 \%$ great in the commercially managed plot. E, Correlation of yield in the commercially managed and nontreated plots. The solid line is the regression fit of: nontreated flower yield $=0.722$ (commercially managed flower yield) +134.2 . All parameters significant at $P<0.0001$ with $R^{2}=0.60 . F$, Relative yield gain from commercial management program in relationship to the severity of Sclerotinia crown rot in the nontreated plot. The solid line represents the regression fit: yield gain $=0.004$ (incidence of plants with Sclerotinia crown rot) -0.01 . The slope parameter was significantly greater than $0\left(P=0.006, R^{2}=0.09\right)$. 
(Table 3), which was entirely through direct effects (Fig. 4B). All variables in the model, with the exception of Sclerotinia crown rot incidence in spring, had significant effects on flower yield; all of these effects were associated with increased canopy density or disease in autumn.
Risk factors for Sclerotinia crown rot outbreaks in spring. Based on the association of autumn canopy density and disease incidence in the path analysis, a logistic regression model was fit based solely on these variables and their interaction. All of the variables were significant $(P \leq 0.067$; Table 4$)$ and the Hosmer and

Table 1. Spearman rank-order correlation of Sclerotinia crown rot incidence with pyrethrum canopy density, early autumn rain events, and flower yield ${ }^{\mathrm{a}}$

\begin{tabular}{|c|c|c|c|c|c|c|c|c|}
\hline \multirow[b]{2}{*}{ Parameters } & \multicolumn{4}{|c|}{ Disease incidence (DI) } & \multicolumn{4}{|c|}{ Canopy density (CD) } \\
\hline & Autumn & Winter & Spring & AUDPS & Autumn & Winter & Spring & Mean \\
\hline \multicolumn{9}{|l|}{ DI } \\
\hline Autumn & & $\ldots$ & $\ldots$ & $\ldots$ & $\ldots$ & $\ldots$ & $\ldots$ & $\ldots$ \\
\hline Winter & $0.62(<0.001)$ & $\ldots$ & $\ldots$ & $\ldots$ & $\ldots$ & $\ldots$ & $\ldots$ & $\ldots$ \\
\hline Spring & $0.47(<0.001)$ & $0.75(<0.001)$ & $\ldots$ & $\ldots$ & $\ldots$ & $\ldots$ & $\ldots$ & $\ldots$ \\
\hline AUDPS & $0.65(<0.001)$ & $0.87(<0.001)$ & $0.92(<0.001)$ & $\ldots$ & $\ldots$ & $\ldots$ & $\ldots$ & $\ldots$ \\
\hline \multicolumn{9}{|l|}{$\mathrm{CD}$} \\
\hline Autumn & $0.39(0.002)$ & $0.33(0.002)$ & $0.48(<0.001)$ & $0.55(<0.001)$ & & $\ldots$ & $\ldots$ & $\ldots$ \\
\hline Winter & $0.23(0.036)$ & $0.25(0.020)$ & $0.5(<0.001)$ & $0.48(<0.001)$ & $0.84(<0.001)$ & $\ldots$ & $\ldots$ & $\ldots$ \\
\hline Spring & $0.04(0.707)$ & $0.02(0.864)$ & $0.26(0.014)$ & $0.23(0.036)$ & $0.58(<0.001)$ & $0.77(<0.001)$ & $\ldots$ & $\ldots$ \\
\hline Mean & $0.25(0.019)$ & $0.24(0.028)$ & $0.47(<0.001)$ & $0.47(<0.001)$ & $0.91(<0.001)$ & $0.96(<0.001)$ & $0.83(<0.001)$ & $\ldots$ \\
\hline Planting date & $-0.13(0.236)$ & $0.06(0.610)$ & $0.03(0.811)$ & $-0.08(0.484)$ & $-0.26(0.014)$ & $-0.22(0.044)$ & $-0.22(0.044)$ & $-0.26(0.012)$ \\
\hline Days with rain & $0.27(0.013)$ & $0.23(0.033)$ & $0.23(0.033)$ & $0.27(0.012)$ & $0.17(0.111)$ & $0.11(0.312)$ & $-0.21(0.048)$ & $0.044(0.685)$ \\
\hline Flower yield & $-0.23(0.037)$ & $-0.1(0.356)$ & $-0.04(0.737)$ & $-0.14(0.212)$ & $0.13(0.257)$ & $0.27(0.014)$ & $0.39(<0.001)$ & $0.27(0.015)$ \\
\hline
\end{tabular}

a Data are from a total of 86 commercial pyrethrum fields assessed during 2010 to 2012 in Tasmania, Australia. AUDPS = area under the disease progress stairs. Days with rain $=$ the number of days with a rain event during the 28 days preceding the autumn disease assessment. Values in parentheses represent significance of relationships.

Table 2. Spearman rank-order correlation of Sclerotinia crown rot incidence, pyrethrum canopy density, and weed prevalence in commercial pyrethrum fields ${ }^{\mathrm{a}}$

\begin{tabular}{|c|c|c|c|c|c|c|}
\hline & \multicolumn{3}{|c|}{ Clover prevalence } & \multicolumn{3}{|c|}{ Weed prevalence } \\
\hline & Autumn & Winter & Spring & Autumn & Winter & Spring \\
\hline \multicolumn{7}{|c|}{ Disease incidence } \\
\hline Autumn & $-0.05(0.680)$ & $0.00(0.973)$ & $0.04(0.712)$ & $-0.03(0.812)$ & $-0.04(0.744)$ & $0.01(0.952)$ \\
\hline Winter & $-0.07(0.550)$ & $0.02(0.859)$ & $0.03(0.780)$ & $-0.09(0.424)$ & $-0.13(0.246)$ & $-0.10(0.339)$ \\
\hline Spring & $-0.21(0.056)$ & $-0.15(0.171)$ & $-0.13(0.224)$ & $-0.19(0.080)$ & $-0.29(0.007)$ & $-0.20(0.059)$ \\
\hline AUDPS & $-0.15(0.177)$ & $-0.08(0.440)$ & $-0.06(0.569)$ & $-0.18(0.091)$ & $-0.27(0.011)$ & $-0.21(0.051)$ \\
\hline \multicolumn{7}{|c|}{ Canopy density } \\
\hline Autumn & $-0.34(0.001)$ & $-0.28(0.010)$ & $-0.26(0.017)$ & $-0.47(<.0001)$ & $-0.47(<0.0001)$ & $-0.35(0.001)$ \\
\hline Winter & $-0.40(<0.001)$ & $-0.40(<0.001)$ & $-0.37(0.001)$ & $-0.45(<0.001)$ & $-0.58(<0.001)$ & $-0.49(<0.001)$ \\
\hline Spring & $-0.28(0.009)$ & $-0.25(0.020)$ & $-0.28(0.008)$ & $-0.35(0.001)$ & $-0.47(<0.001)$ & $-0.45(<0.001)$ \\
\hline Mean & $-0.38(<0.001)$ & $-0.35(0.001)$ & $-0.34(0.001)$ & $-0.47(<0.001)$ & $-0.56(<0.001)$ & $-0.47(<0.001)$ \\
\hline
\end{tabular}

${ }^{a}$ Data are from a total of 86 commercial pyrethrum fields assessed during 2010 to 2012 in Tasmania, Australia. Assessments were conducted once in each of autumn, winter and spring. AUDPS = area under the disease progress stairs. Values in parentheses represent significance of relationships.

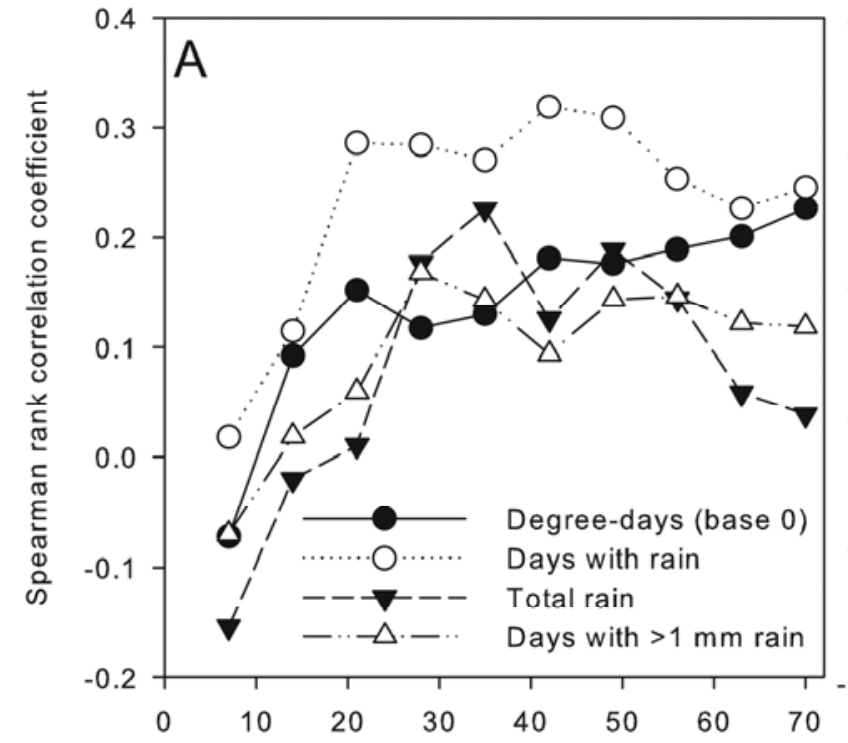

Days prior to disease assessment

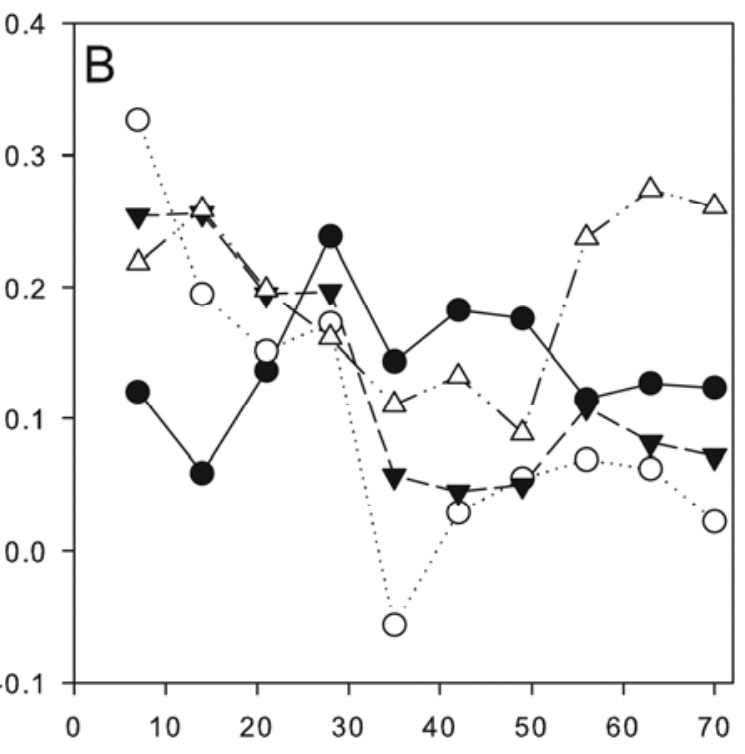

Days prior to disease assessment

Fig. 3. Magnitude of Spearman rank correlation coefficient of incidence of $\mathbf{A}$, pyrethrum plants with Sclerotinia crown rot or $\mathbf{B}$, pyrethrum canopy density in autumn verses weather variables over varying periods of time. Data are from a total of 86 commercial pyrethrum fields assessed during 2010 to 2012 in Tasmania, Australia. 
Lemeshow test indicated an adequate fit $(P=0.785)$. Area under receiver operating characteristic curve was 0.828 , indicating reasonable prediction accuracy. Assuming a nominal classification threshold of a model estimated probability of 0.5 , spring disease risk was correctly predicted in $72 \%$ of the fields (Fig. 5). Among the 45 fields where the true incidence of Sclerotinia crown rot exceeded $2 \%$ during spring, $72.3 \%$ of fields were correctly classified by the model as being above this threshold. Among the 41 fields that had true disease status less than $2 \%$ in spring, $71.8 \%$ were correctly classified by the model.

Influence of Sclerotinia crown rot on regrowth after harvest. Canopy survival was negatively correlated with disease incidence, expressed as AUDPS $(S=-0.42, P=0.005)$, and incidence in the winter and spring sampling periods of the previous season $(S=$ $-0.32, P=0.036)$ but not in autumn $(S=-0.25, P=0.101)$. Mean preharvest canopy density, weed prevalence, and clover prevalence had no significant relationship with canopy survival $(S=-0.25$ to $0.08, P \geq 0.103$ ). Within individual sampling periods (autumn, winter, and spring), neither canopy density nor weed prevalence was significantly correlated with canopy survival $(S=-0.19$ to $0.15, P \geq 0.217)$. Spring clover prevalence was negatively correlated with canopy survival $(S=-0.34$ to $0.15, P=0.026$ ), but not autumn or winter clover prevalence $(S=-0.05$ and -0.25 , respectively, $P \geq 0.118$ ).

Mixed modeling indicated a linear relationship between canopy survival and AUDPS (Fig. 6), defined by the equation $y_{C S}=58.02-$ $0.759 \times$ AUDPS, where $y_{C S}$ represents the percent canopy survival for given plot. All parameter estimates differed significantly from 0
$(P \leq 0.006)$. Sclerotinia crown rot management strategy (commercial versus nontreated) did not significantly alter this relationship $(P=0.187)$.

\section{Discussion}

The results of this study established the association of Sclerotinia crown rot with pyrethrum flower yield, validated the efficacy of commercial management tactics for the disease, and identified determinants of disease development and crop damage. Commercial management efforts were demonstrated to have a significant but modest effect on the incidence of Sclerotinia crown rot, although the overall effect on flower yield was minimal. Averaged over all sites, we found no evidence to suggest an improvement in yield from any intensity of fungicide applications as made in practice by the pyrethrum growers. There was a weak trend for higher flower yield in commercially managed plots dependent on the relative severity of the disease, especially under more severe disease pressure.

The overall muted effect of commercial management efforts may be because of an inherent lack of efficacy of the fungicides, because Sclerotinia crown rot has a minimal effect on yield, or because insufficient levels of disease were present to detect yield improvements from fungicide applications. Although 24 fields (27.9\%) received no fungicide applications in the commercially managed plots, there was evidence for some disease suppression among the fields that received at least one fungicide application. This suggests that the current fungicide program does provide a level of control over Sclerotinia crown rot, and that lack of efficacy
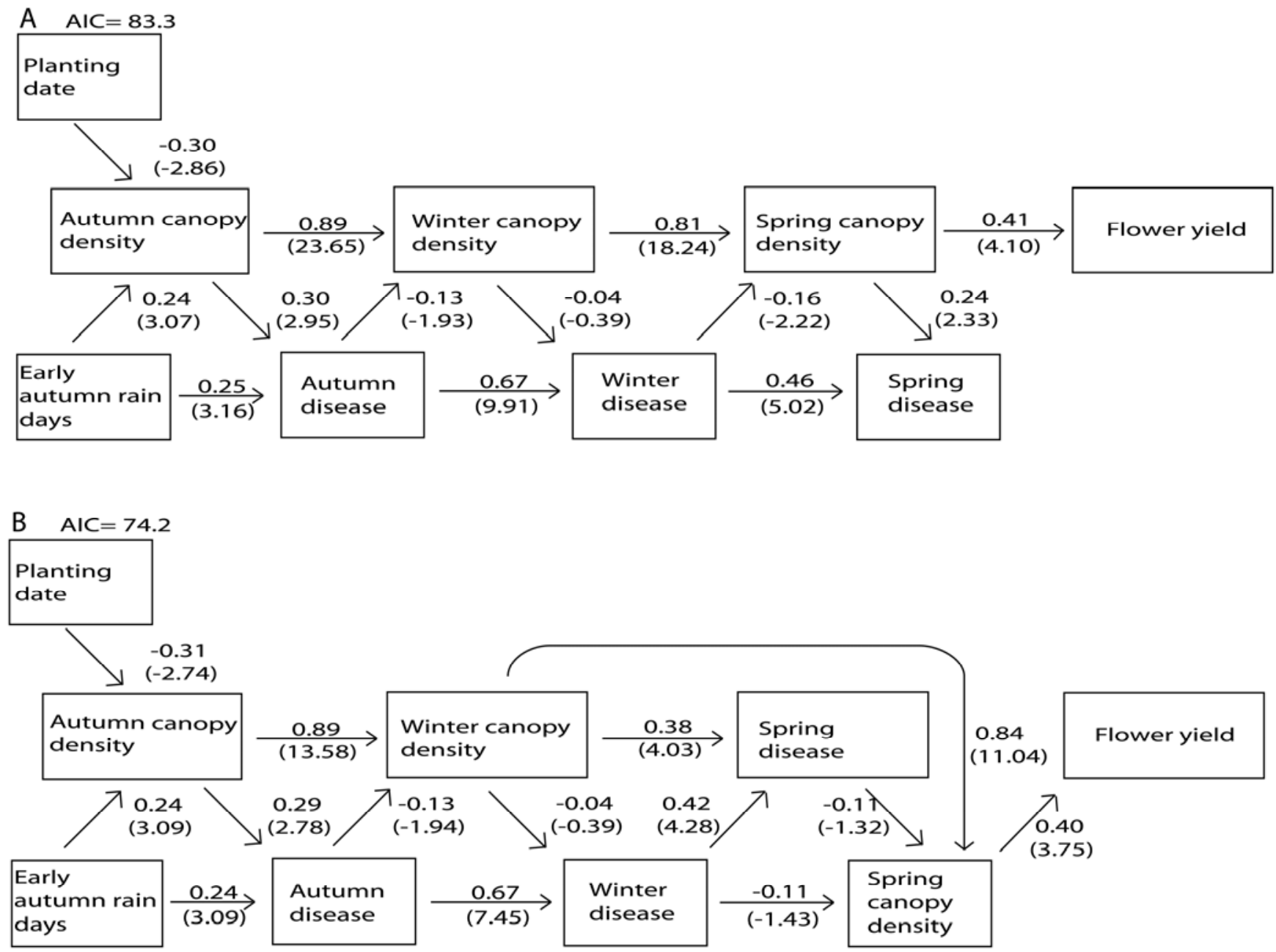

Fig. 4. Path diagrams expressing two hypotheses for interrelationships between variables affecting canopy development, Sclerotinia crown rot, and flower yield in pyrethrum. Standardized path coefficients and associated $t$ statistics are presented numerically for each path. Values of $t>|2|$ indicate path coefficients significantly $(\alpha=0.05)$ greater than 0 . The value of Akaike's Information Criterion (AIC) is shown numerically; smaller values of AIC indicate the best-fitting and parsimonious model. 
of the program cannot be a major factor for the little improvements in yield. The shallow slopes of the regression of yield gain versus disease incidence (Fig. 2E) generally support the concept that commercial disease management efforts provide little yield gain and that these yield gains are most apparent under relatively severe disease pressure. Thus, Sclerotinia crown rot management may still provide benefits as a risk avoidance strategy, especially when targeted to high risk sites.

Given the importance of spring canopy density on flower yield as determined by correlation and path analyses, collectively, these studies suggest that Sclerotinia crown rot reduces flower yield only when the disease substantially reduces spring canopy density. In field crops, crop damage from disease is often the result of diminished photosynthetic capacity or efficiency (6). Measurements of healthy area duration of the host typically indicate a monotonic relationship between healthy area duration and yield. The relationship between biomass production and healthy area absorption of radiation is asymptotic and generally affected less in plants with high green leaf areas compared with plants with low green leaf area $(6,10)$. Given the overall lack of flower yield improvement from even the most intensive commercial management of the disease, pyrethrum plants that survive Sclerotinia crown rot appear to have a substantial capacity for within- or between-plant compensation for reductions in health leaf area.

The path analysis provides a framework for conceptualizing both factors that contribute to disease development and the conditions that may eventually lead to crop damage. The potential for severe outbreaks of Sclerotinia crown rot in spring (when flower yield is directly affected by canopy density) is linked to antecedent conditions that increase canopy density and inoculum levels during autumn. In the perennial pyrethrum cropping system, canopy density in autumn is influenced positively by earlier planting date and autumn rain, and negatively by the prevalence of weeds. In this aspect, development of Sclerotinia crown rot in pyrethrum appears similar to the disease in annual cropping systems, where disease development is driven by extensive host canopies and factors that increase yield potential but also soil moisture $(14,23)$. Germination of Sclerotinia spp. sclerotia is favored by soil moisture $(7,31)$, which supports the observed direct and indirect effects of autumn rain on autumn disease incidence in the path analysis. In pyrethrum, Sclerotinia crown rot epidemics may occur over an extended period of time. Path analysis suggests that the duration and intensity of the overall outbreak is ultimately linked to canopy density in autumn, with a total effect of 0.4 (Table 3), mediated entirely through indirect effects on later canopy and disease development. It is not surprising, then, that canopy density in autumn also has an indirect effect on flower yield (0.27) and that the incidence of Sclerotinia crown rot in autumn is predicted to have a negative, albeit small, effect on yield (-0.084; Table 3$)$. It is also relevant to note that pyrethrum canopy density, and not total vegetative canopy, was associated with disease development. Prevalence of all weeds and, specifically, clover, the single most common weed observed and a known host of Sclerotinia spp. $(3,29)$, were negatively correlated with both pyrethrum canopy density and the incidence of Sclerotinia crown rot. Disease development was associated with pyrethrum canopy density but not total vegetative canopy, which took into account the ground area covered by other species, such as weeds. Prevalence of broadleaf weeds was negatively correlated with both pyrethrum canopy density and Sclerotinia crown rot incidence.

On this basis, we developed a simple risk algorithm based on the density of pyrethrum plants in autumn and incidence of diseased plants during the same period. These are factors that are relatively easy to measure and can provide an approximate risk of Sclerotinia crown rot in spring, which was $72 \%$ accurate in the data sets used for constructing the model. Identification of risk factors in autumn may be useful for more strategic and rationalized deployment of fungicides, particularly given the general lack of yield improvement from fungicide applications. Other potential predictor variables were considered but autumn canopy density and disease incidence were selected for pragmatic reasons. Based on the path analysis and general biology of diseases caused by Sclerotinia spp., host canopy density and primary inoculum are strongly associated with the ultimate course of disease outbreaks. Weather variables or direct measures of sclerotial densities could be undertaken but add cost and complexity to farm management. Canopy density and

Table 3. Total effect of pyrethrum canopy density, inoculum, and weather variables on other variables and flower yield deduced from path analysis ${ }^{\mathrm{a}}$

\begin{tabular}{|c|c|c|c|c|c|c|c|c|}
\hline Var & ACD & AD & WCD & WD & SCD & SD & Date & Rain \\
\hline $\mathrm{ACD}$ & 0 & 0 & 0 & 0 & 0 & 0 & $-0.30(0.004)$ & $0.24(0.002)$ \\
\hline $\mathrm{AD}$ & $0.30(0.003)$ & 0 & 0 & 0 & 0 & 0 & $-0.09(0.044)$ & $0.32(0.001)$ \\
\hline WCD & $0.85(0.0001)$ & $-0.13(0.054)$ & 0 & 0 & 0 & 0 & $-0.26(0.005)$ & $0.17(0.004)$ \\
\hline WD & $0.17(0.100)$ & $0.68(0.0001)$ & $-0.04(0.696)$ & 0 & 0 & 0 & $-0.05(0.155)$ & $0.21(0.003)$ \\
\hline SCD & $0.66(0.0001)$ & $-0.21(0.004)$ & $0.81(0.0001)$ & $-0.16(0.026)$ & 0 & $-0.11(0.188)$ & $-0.20(0.007)$ & $0.11(0.013)$ \\
\hline SD & $0.40(0.0001)$ & $0.23(0.003)$ & $0.37(0.0001)$ & $0.41(0.0001)$ & 0 & 0 & $-0.12(0.017)$ & $0.15(0.005)$ \\
\hline Yield & $0.27(0.0002)$ & $-0.085(0.020)$ & $0.33(0.0001)$ & $-0.06(0.049)$ & $0.41(0.0001)$ & $-0.05(0.209)$ & $-0.08(0.028)$ & $0.04(0.036)$ \\
\hline
\end{tabular}

a Total effect is the sum of direct and indirect effects. Direct effects are represented by arrows connecting two variables in Figure 4. Indirect effects are the association of one variable with another mediated through other variables. Indirect effects are calculated as the sum of the products of the path coefficients linking two variables, or total effect. Abbreviations: Var = endogenous variables, $\mathrm{ACD}=$ autumn canopy density, $\mathrm{AD}=$ autumn disease, $\mathrm{WCD}=\mathrm{winter}$ canopy density, $\mathrm{WD}=$ winter disease, $\mathrm{SCD}=$ spring canopy density, $\mathrm{SD}=$ spring disease, Date $=$ planting date, Rain $=$ early autumn rain days, and Yield $=$ flower yield.

Table 4. Logistic regression parameter estimates and significance statistics for estimating the probability of an outbreak of Sclerotinia crown rot on pyrethrum during spring

\begin{tabular}{lcccccc}
\hline & \multicolumn{9}{c}{ Analysis of maximum likelihood estimates } \\
\cline { 2 - 6 } Parameter $^{\mathbf{a}}$ & $\mathbf{D F}$ & Estimate & $\mathbf{S E}^{\mathbf{b}}$ & Wald $\boldsymbol{\chi}^{\mathbf{2}}$ & $\boldsymbol{P}_{\text {value }}$ & AUROC $^{\mathbf{c}}$ \\
\hline Intercept & 1 & -5.0366 & 1.575 & 10.221 & 0.001 & 0.828 \\
Pyrethrum canopy density in autumn & 1 & 0.0663 & 0.022 & 9.148 & 0.003 & $\ldots$ \\
Disease incidence in autumn & 1 & 300.4 & 143.0 & 4.414 & 0.036 & $\ldots$ \\
Disease incidence $\times$ canopy density & 1 & -3.0589 & 1.672 & 3.346 & 0.067 & $\ldots$ \\
\hline
\end{tabular}

a Model, including isolation frequency of pathogen. Data for fitting the models were obtained from nonfungicide-treated plots in a total of 86 commercial pyrethrum fields in Tasmania, Australia during 2010 to 2012. Data sets were classified into two classes of spring disease incidence (above or below $2 \%$ disease incidence) based on the current provisional fungicide action threshold for Sclerotinia crown rot. The Hosmer and Lemeshow goodness-of-fit test indicated an adequate fit of the model $\left(\chi^{2}=3.96\right.$, df $\left.=7, P=0.785\right)$.

b Standard error.

c Area under the receiver operating characteristic curve (AUROC) is an overall measure of classification accuracy. AUROC is equal to 1 for models with perfect prediction, and models that classify severe outbreaks no better than by chance have an AUROC of 0.5 . 
disease incidence in autumn essentially integrate previous weather and inoculum factors, and provide a more direct measure of disease risk than surrogate variables (e.g., rain, soil moisture, or number of sclerotia present).

Development of Sclerotinia crown rot in first-year crops was associated with reduced canopy density after harvest. As shown here, flower yield is determined mostly by spring canopy density,

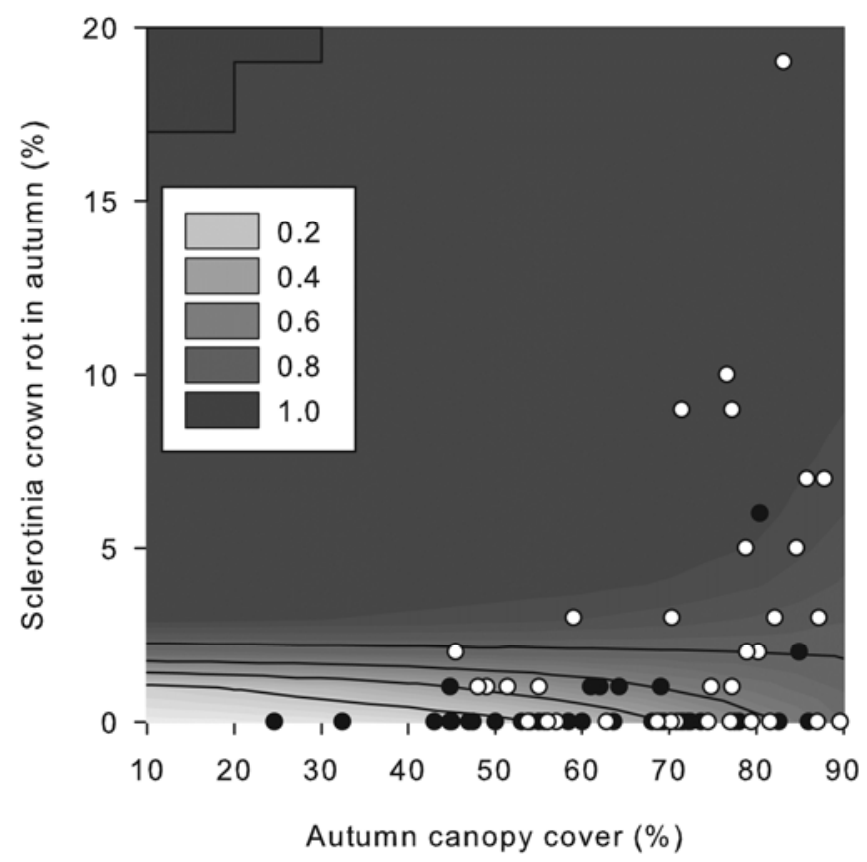

Fig. 5. Contour plot illustrating the relationship between pyrethrum canopy cover, incidence of Sclerotinia crown rot in autumn, and predicted probability of a disease outbreak in spring exceeding a provisional fungicide action threshold of $2 \%$. Contour lines are estimated probabilities of the incidence of Sclerotinia crown rot exceeding 2\%; model parameters are given in Table 3. Open circles indicate pyrethrum fields where disease was above the $2 \%$ in spring and closed circles indicate fields that were below the threshold.

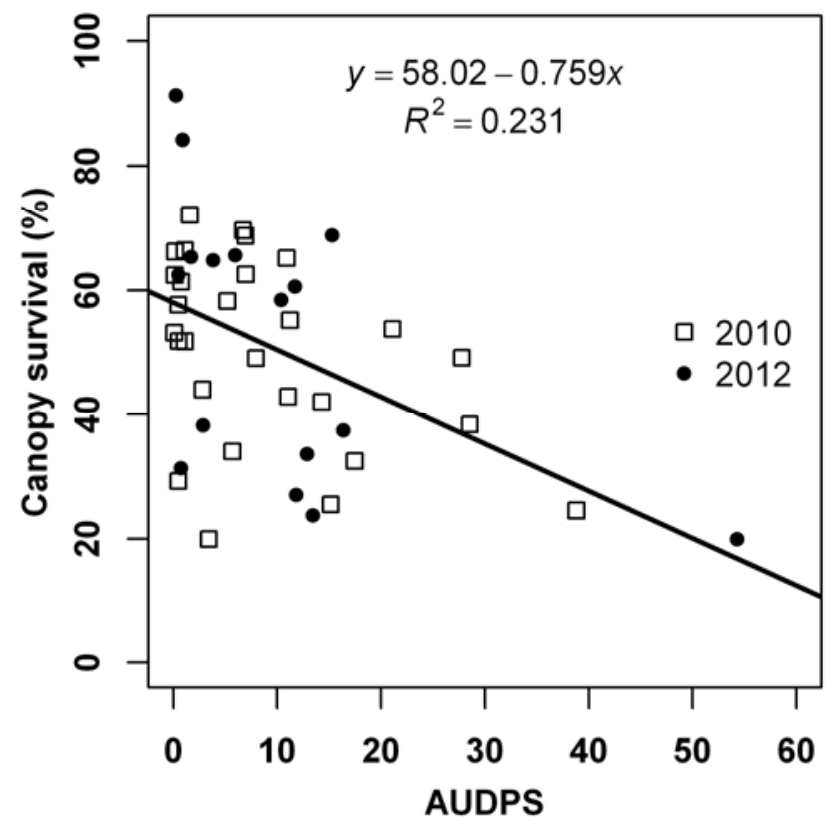

Fig. 6. Relationship between Sclerotinia crown rot (expressed as area under the disease progress stairs, AUDPS) and the relative decrease in pyrethrum canopy coverage from the autumn preceding first harvest to the autumn after harvest (canopy survival). Canopy survival is defined as (after-harvest autumn canopy density)/(preharvest autumn canopy density) $\times 100$. Data are from 22 commercial pyrethrum fields assessed during 2010 to 2013 in Tasmania, Australia. of which autumn canopy density is a correlate. As a perennial crop, recovery of plants following harvest is an important factor determining the productive life of a pyrethrum crop. Crops that recover poorly from harvest are often deemed uneconomically viable and terminated. For a crop where the greatest production costs are associated with planting and establishment, early terminations can represent a substantial loss of potential yield and revenue. Results obtained here suggest that development of Sclerotinia crown rot preceding the first harvest may reduce recovery of pyrethrum after harvest, even where yield in the first season is not compromised. Regrowth and persistence after harvest is linked to reserves of carbohydrates or nitrogen within the root system of a number of perennial crop plants, including perennial ryegrass (5), alfalfa (30), and chicory (11). In pyrethrum, defoliation due to Sclerotinia crown rot would require surviving plants to utilize their root system for vegetative growth and flowering during late spring and summer. This, in turn, could deplete nutrient sources after harvest and reduce recovery and persistence. If true, management of Sclerotinia crown rot during the early autumn period of young crops may be an important factor in stand persistence. This is an area that deserves further study. Diminished canopy recovery following the first harvest also provides an explanation for the lack of Sclerotinia crown rot observed in the subset of fields evaluated in the ensuing season.

Based on risk factors identified in this research and paths leading to disease development and flower yield, disease management efforts appear best targeted to early stages of the cropping cycle by reduction of initial inoculum and disease escape through manipulation of canopy density. Fungicide applications and other disease management efforts appear best targeted to fields at the highest risk of the disease; specifically, early-planted fields with well-developed plant canopies and Sclerotinia crown rot present during early autumn. Given the apparent yield-compensation ability of pyrethrum, critical evaluation of optimal planting rates and dates are warranted to identify minimal plant populations that still enable realization of commercially viable yield and maximize crop persistence.

\section{Acknowledgments}

This project was funded by the Australian Research Council Linkage program in partnership with Botanical Resources Australia, Pty. Ltd. (project LP100100529) and United States Department of Agriculture-Agricultural Research Service CRIS 5358-21000-035-00. We thank the growers and field officers who allowed access to their fields that made this research possible; C. Palmer (Tasmanian Institute of Agriculture) for excellent technical assistance; and B. Nelson (North Dakota State University), M. Twomey (Oregon State University), and W. Nelson (Plant and Food Research Ltd.) for their review and suggestions that improved this manuscript.

\section{Literature Cited}

1. Adams, P. B., and Ayers, W. A. 1979. Ecology of Sclerotinia species. Phytopathology 69:896-899.

2. Bolton, M. D., Thomma, B., and Nelson, B. D. 2006. Sclerotinia sclerotiorum (Lib.) de Bary: biology and molecular traits of a cosmopolitan pathogen. Mol. Plant Pathol. 7:1-16.

3. Ekins, M. G., Aitken, E. A. B., and Goulter, K. C. 2005. Identification of Sclerotinia species. Australas. Plant Pathol. 34:549-555.

4. Elliott, M. 1995. Chemicals in insect control. Pages 3-31 in: Pyrethrum Flowers: Chemistry, Toxicology and Uses. J. E. Casida and G. B. Quistad, eds. Oxford University Press, New York.

5. Fulkerson, W. J., and Donaghy, D. J. 2001. Plant-soluble carbohydrate reserves and senescence-key criteria for developing an effective grazing management system for ryegrass-based pastures: a review. Aust. J. Exp. Agric. 41:261-275.

6. Gaunt, R. E. 1995. The relationship between plant disease severity and yield. Annu. Rev. Phytopathol. 33:119-144.

7. Hao, J. J., Subbarao, K. V., and Duniway, J. M. 2003. Germination of Sclerotinia minor and $S$. sclerotiorum sclerotia under various soil moisture and temperature combinations. Phytopathology 93:443-450.

8. Hutchinson, M. F. 1995. Interpolating mean rainfall using thin-plate smoothing splines. Int. J. Geogr. Inf. Syst. 9:385-403.

9. Jeffrey, S. J., Carter, J. O., Moodie, K. M., and Beswick, A. R. 2001. Using spatial interpolation to construct a comprehensive archive of Australian climate data. Environ. Model. Software 16:309-330.

10. Johnson, K. B. 1987. Defoliation, disease and growth: a reply. Phytopathology 77:1495-1497. 
11. Li, G. D., Kemp, P. D., and Hodgson, J. 1997. Biomass allocation, regrowth and root carbohydrate reserves of chicory (Cichorium intybus) in response to defoliation in glasshouse conditions. J. Agric. Sci. 129:447-458.

12. Loehlin, J. C. 1987. Latent Variable Models, An Introduction to Factor, Path, and Structural Analysis. Lawrence Erlbaum Associates, Hillsdale, NJ.

13. Macdonald, W. L. 1995. Pyrethrum flowers-production in Australia. Pages 55-66 in: Pyrethrum Flowers: Chemistry, Toxicology and Uses. J. E. Casida and G. B. Quistad, eds. Oxford University Press, New York.

14. Mila, A. L., Carriquiry, A. L., Zhao, J., and Yang, X. B. 2003. Impact of management practices on prevalence of soybean Sclerotinia stem rot in the north-central United States and on farmers' decisions under uncertainty. Plant Dis. 87:1048-1058.

15. O'Malley, T. B. 2012. Epidemiology and management of flower diseases of pyrethrum. Ph.D. diss. University of Tasmania, Burnie, Tasmania, Australia.

16. Pethybridge, S. J., Gent, D. H., Esker, P. D., Turechek, W. W., Hay, F. S., and Nutter, F. W. 2009. Site-specific risk factors for ray blight in Tasmanian pyrethrum fields. Plant Dis. 93:229-237.

17. Pethybridge, S. J., Gent, D. H., Groom, T., and Hay, F. 2013. Minimizing crop damage through understanding relationships between pyrethrum phenology and ray blight disease severity. Plant Dis. Online publication. doi:/10.1094/PDIS-11-12-1102-RE

18. Pethybridge, S. J., Hay, F. S., Esker, P. D., Gent, D. H., Wilson, C. R., Groom, T., and Nutter, F. W. 2008. Diseases of pyrethrum in Tasmania: challenges and prospects for management. Plant Dis. 92:1260-1272.

19. Pethybridge, S. J., Hay, F. S., and Gent, D. H. 2010. Characterization of the spatiotemporal attributes of Sclerotinia flower blight epidemics in a perennial pyrethrum pathosystem. Plant Dis. 94:1305-1313.

20. Purdy, L. H. 1979. Sclerotinia sclerotiorum - history, diseases and symptomatology, host range, geographic distribution, and impact. Phytopathology 69:875-880.

21. Savary, S., Teng, P. S., Willocquet, L., and Nutter, F. W. 2006. Quantifica- tion and modeling of crop losses: a review of purposes. Annu. Rev. Phytopathol. 44:89-112.

22. Schneider, C. A., Rasband, W. S., and Eliceiri, K. W. 2012. NIH Image to ImageJ: 25 years of image analysis. Nat. Methods 9:671-675.

23. Schwartz, H. F., and Steadman, J. R. 1978. Factors affecting sclerotium populations of, and apothecium production by, Sclerotinia sclerotiorum. Phytopathology 68:383-388.

24. Scott, J. B., Pethybridge, S. J., and Hay, F. 2011. Pyrethrum yield estimation by digital image analysis. (Abstr.) Phytopathology 101:S162

25. Simko, I., and Piepho, H. P. 2012. The area under the disease progress stairs: calculation, advantage, and application. Phytopathology 102:381389.

26. Stern, V. M., Smith, R. F., van den Bosch, R., and Hagen, K. S. 1959. The integrated control concept. Hilgardia 29:81-101.

27. Stone, R. C., Hammer, G. L., and Marcussen, T. 1996. Prediction of global rainfall probabilities using phases of the southern oscillation index. Nature 384:252-255.

28. Turechek, W. W. 2004. Nonparametric tests in plant disease epidemiology: characterizing disease associations. Phytopathology 94:1018-1021.

29. Vleugels, T., Baert, J., and van Bockstaele, E. 2013. Morphological an pathogenic characterization of genetically diverse Sclerotinia isolates from European red clover crops (Trifolium pratense L.). J. Phytopathol. 161:254 262.

30. Volenec, J. J., Ourry, A., and Joern, B. C. 1996. A role for nitrogen reserves in forage regrowth and stress tolerance. Physiol. Plant. 97:185-193.

31. Wu, B. M., and Subbarao, K. V. 2008. Effects of soil temperature, moisture, and burial depths on carpogenic germination of Sclerotinia sclerotiorum and S. minor. Phytopathology 98:1144-1152.

32. Zito, S. W., Zieg, R. G., and Staba, E. J. 1983. Distribution of pyrethrins in oil glands and leaf tissue of Chrysanthemum cinerariafolium. Planta Med. 47:205-207. 